\title{
Relationships with Self and Societal Analysis Towards Emotional Dynamics Amongst Teaching Professionals
}

\author{
Dr. Lakshmipriya Soundararajan \\ Associate Professor, Department of Management Studies, \\ KG College of Arts and Science, Coimbatore, Tamil Nadu, India
}

\begin{abstract}
Emotional Intelligence (EI) is an ability of teaching professionals to perceive and assess series of emotions in the form of emotional cues. The research studies conducted on emotional intelligence revealed that it has been positively connected with success in academic life and recently linked with effective teaching and learning. Emotional traits like empathy, social skills, inter-personal skills, emotional awareness and other tacit knowledge predict their performances towards thriving career where self and societal analysis plays a effervescent role. The current research attempted to examine the relationships between background variables with self and societal analysis amongst teaching professionals to achieve optimum learning for personal and professional enrichment. The findings revealed the link between background variables with emotional dynamics of teaching professionals. Moreover, the results provided considerable support of hypotheses and confirmed the relationships among background variables, towards personal and professional accomplishments through self and societal analysis.
\end{abstract}

Keywords: Emotional intelligence; Emotional cues; Empathy; Optimum Learning; Professional enrichment; Self; Societal analysis; Teaching professionals.

\section{INTRODUCTION:}

Emotional Intelligence (EI) is a mounting area of behavioral research, which focuses on the minds of general public, corporate, commercial world, scientific and research community. The requirement of emotional intelligence skills reflects the transformation of social attitudes in the field of education. Emotional intelligence is an ability to understand oneself and others, particularly in understanding and usage of information about emotional states with competence. In this millennium of emerging environment, professionalism demand teaching professionals to be innovative in attitude, flexible in approach, rejuvenating themselves with periodical developments in their subject area. At the same time teaching, professionals should be capable of recognizing the values of human potential, understanding diverse needs of learners to enrich an environment for growth. In reality the dream of learning society becomes certain only when teaching professionals are well equipped with professional, practical, emotional, intellectual and communication skills. Moreover, teaching professionals with high intelligent quotient may not be inevitably rational on emotional competencies. Hence, teachers with high emotional quotient seems to exhibit open and free expression of ideas which leads to creativity and mutual respect (Singh, 2002). The individual who are emotionally competent can manage, recognize and respond effectively to the feelings of others and can tolerate frustration better (Elias, 1992). Measuring emotional intelligence is not easier than measuring any other human qualities. Thus, the role of emotional intelligence amongst teaching community is very crucial as emotional skills are linked with classroom management, performance and teacher retention factors, which results in long term effects on their teaching career. It is a composite psychological and physiological experience involving a state of mind and its interaction with individual and their background. Emotion primarily involves conscious experience, physiological arousals and expressive behaviours amongst human being (Myers, 2001). Also, emotion is associated with mood, character, personality and motivation. The feelings and expressions are the key elements of emotional life 
(Cowie, 2011). Moreover, emotional expressions are crucial to development and regulation of interpersonal and intra-personal relationships. Emotional regulation is an individual effort to manage, inhibit, enhance and modulate emotions. Thus, emotional expressions are the social effects of emotional regulation and ethical considerations, which determines nature and appropriateness of emotions for cultivating ethical and moral character in oneself and others.

\section{Reviews on Teaching Professionals \& Self and Societal Analysis through Emotional Intelligence}

Professionalism is related to an improvement in quality of service rather than enhancement of status (Day, 2007). Teaching professionalism is interpreted as a professional work with its sociological, ideological and educational dimensions that aims at achieving the highest standards in teaching profession, which is entirely based upon professional formation, knowledge, skills and values (Derksen, 2010). In addition to that, teaching professional influences the personality of every student / learner. Thus, the current educational system is a hybrid range of conservative and modern generation type. The teaching professionals have to perform multiple and complex roles to address educational, financial, psychological, societal and welfare needs (Cherniss, 2010). It has to be noted that when teaching professionals are emotionally intelligent, they can be able to manage their emotional maturity among their learners / students. Thus, it is apparent to have more number of researches on emotional intelligence among teaching professionals, which aid them to progress and sustain in their working environment. The recent studies have acknowledged that the roles played by teaching professionals showed both positive and negative impact on teaching effectiveness (Day, 2007). In particular, the research studies have looked into teachers' general and andragogical knowledge, behaviours, personalities, beliefs, attitudes, selfefficacy and motivation which have examined their impact towards teaching effectiveness. Mayer \& Salovey (1997) specified emotional intelligence encompasses four inter-related abilities involved in processing of emotional information like perceiving emotions, using emotions to facilitate thinking, understanding emotions and regulating their own emotions and emotions of others. The past literatures on self-analysis and societal-analysis which are required for the assessment of their actual capacity that focuses on mental ability for professional achievement. These abilities are quite important for social interaction because emotions serve as communicative, social functions, conveying information about thought and intention of an individual. A study on personal tendencies using perception, processing and arranging emotional information included the qualities related to person's own internal evaluation, which revealed that certain behaviours and characteristics like optimism, secure initiative and empathy are some of the characteristic features of emotional intelligence (Ozer et al. 2016). Goleman (1995) expressed that self-analysis serves as the foundation for psychological and emotional advancement needed to achieve success. . Selfanalysis is the ability of an individual to identify and understand their needs, emotions, moods, drives, strengths, weaknesses, as well as their effect on other people. Also, (Goleman, 1998) specified that selfmanagement is the ability of an individual to manage or redirect disruptive impulses and moods, as well as distressing feelings. The competencies of emotional intelligence were self-management including emotional self-control, conscientiousness, trustworthiness, adaptability, and innovation. Boyatzis et al. (2002) suggested that emotional intelligence is observed when a person demonstrates the competencies which constitute self-analysis, selfawareness, self-management, social analysis, social awareness, and social skills at appropriate times and ways in sufficient frequency to be effective in the situation. Greenberg in 2009 identified emotional intelligence in particular emotional self-awareness allows teachers to recognize and understand their emotions in classroom and to anticipate the effects of their emotional expressions and interactions with others. In addition to that, Palmer in 2010 identified in his research study that teaching professionals required to have awareness in their feelings, morals and approach towards their behaviour for professional enrichment. Igbo et al. (2016) specified that emotional skill development is helpful in assisting students to succeed in life. Therefore, students who are skilled in these areas not only adjust academically but also in their social interaction with people.

\section{Need \& Relevance}

Emotions are the reaction to a stimuli or circumstances that strongly affects the personality. Emotional intelligence seems to be a key aspect in understanding an environment, which motivates and desires an individual for better performance. The 
research indicates that higher levels of emotional intelligence are associated with series of positive emotional upshots. Moreover, teaching professionals who often express their individual emotional state infers the emotional expressions of others which provide their students / learners and environment with powerful mechanism for emotional regulation. Emotional intelligence is an exceptional area with regard to research and development especially among teaching professionals who create and mould current and future society. It is to be noted that, regardless of discrepancies between conceptions of emotional intelligence, it is clear that emotional intelligence has been distinct from other standard intelligence. Emotional intelligence is considered as essential for successful living. Self-analysis is the foundation upon which the other components of emotional intelligence are built. Emotional intelligence facilitates teaching professionals to achieve success in every part of life, whether it is workplace, home or society. It provides foundation to build emotions in a balanced way to handle diverse situations in an effective approach. Apart from teaching, teaching professionals have to perform many other roles like counseling, mentoring the students, performance supervision, knowledge transfer apart from studies, guiding students with latest technologies, continuous learning and development of their own skills, contribution in research work, publications, administrative work and many more. Emotional intelligence correlate with social and academic adjustment of newly joined teaching professionals. The study will be of immense benefit to researchers and teachers in educational, social and other areas of psychological setting. Thus, self-analysis and societal analysis for emotional stability is vital for better performance and professional accomplishment.

\section{Objectives}

To find the relationships of various background variables with self and societal analysis towards emotional dynamics amongst teaching professionals

\section{Assumptions \& Hypotheses}

Teaching professionals need to face the complexities in their day-to-day life. These intricacies have given rise to psycho-somatic problems like anxiety, tension, frustration and emotional futility in their activities. Emotional intelligence is a personal capacity to perform a psychological task. Moreover, EI competencies like self-analysis, self-awareness, selfexpression, self-confidence, self-motivation, conscientiousness, societal competence, transparency, skills management and empathy have been argued as noteworthy for 'self' and 'societal realization'. Hence, emotions are the critical ingredients for optimal information processing, social communication, written communication, motivation, attention, concentration, memory, critical thinking skills, creativity, behaviour, physical health, and survival (Goleman 1995b). A certain level of emotional intelligence is necessary to for self and societal analysis towards application of positive climate in personal and professional living (Sutton 2006). The teaching professional's understanding of impact of socio-emotional learning depends on their selfawareness through systematic teaching and learning behavior.

\section{$\mathrm{H}_{1}$ : There found relationship between various background variables with EI on self and societal analysis}

\section{Procedure}

The researcher has administered descriptive research method and survey research design with structured interview schedule to assess emotional intelligence amongst teaching professionals to achieve the objectives of this research study. The sampling has been done through the self-financing institutions in Coimbatore district at Tamil Nadu. The researcher has administered stratified random sampling across the definite universe and interviewed 263 respondents $(\mathrm{N}=263 ; 96$ respondents from arts \& science colleges; 122 respondents from engineering colleges and 45 respondents from core management colleges (BSchools)) constituting over 20 percent (one-fifth) of the total populace (1314). The data coded were analyzed using Statistical Package for Social Sciences (SPSS 20.0) to find the significance of mean difference, correlation ( $\mathrm{r}$ ), regression $(\mathrm{R})$ and one-way analysis of variance (ANOVA) has been used to analyze measurement model and goodness to fit indices.

\section{Variables Used}

Background Variables (BV)

C- College; MS- Marital Status; H- Hobbies; TESRTeaching and Evaluation Skills Required; SDCASkill Development Courses Attended; NPP- Number of M.Phil / Ph.D's Produced.

\section{Dependent Variables (DV)}

EISA- EI on Self-Analysis \& EISOA- EI on SocietalAnalysis. 
EI on Self-Analysis (EISA): Emotional intelligence on self-analysis is defined as an evaluation of individuals' thoughts and behaviour. It is an ability to recognize and understand their own emotions and effects on their 'self' and 'others' (Goleman, 1997).

EI on Societal-Analysis (EISOA): Emotional intelligence on societal analysis is a combination of aspects like lifestyle, motivation, cultural, moral and ethical values of a human. Emotional intelligence with social and emotional analysis involves delineate of social and emotional skills, which are deemed essential for functioning of positive relationships and developing effectiveness to improve and encourage societal analysis skills (Elias 1997).

\section{Statistical Analyses}

Table 1 Chi-Square test of background variables with EI on self and societal analysis

\begin{tabular}{|c|c|c|c|c|c|}
\hline \multirow{2}{*}{$\mathbf{B V}$} & DV & $\chi^{2}$ & dff & $\mathrm{p}$ & Inference \\
\hline \multirow{2}{*}{$\mathrm{C}$} & EISA & 34.66 & 6 & 0.00 & $\mathrm{~S}$ \\
\cline { 2 - 6 } & EISOA & 13.82 & 4 & 0.00 & $\mathrm{~S}$ \\
\hline $\mathrm{MS}$ & EISA & 22.94 & 6 & 0.00 & $\mathrm{~S}$ \\
\hline $\mathrm{H}$ & EISA & 65.39 & 21 & 0.00 & $\mathrm{~S}$ \\
\hline SDCA & EISA & 25.78 & 15 & 0.04 & $\mathrm{~S}$ \\
\hline NPP & EISA & 35.80 & 15 & 0.00 & $\mathrm{~S}$ \\
\hline
\end{tabular}

NS-Not Significant $(p>0.05)$; S-Significant $(p<0.05)$

Background Variables (BV): C- College; MSMarital Status; H- Hobbies; TESR- Teaching and Evaluation Skills Required; SDCA- Skill Development Courses Attended; NPP- Number of M.Phil / Ph.D's Produced. Dependent Variables (DV): EISA- EI on Self-Analysis; EISOA- EI on Societal-Analysis.

The above Table 1 shows that the college where teaching professionals employed, age and nativity were associated with emotional intelligence on societal-analysis. Emotional intelligence on application learning skills were strongly and significantly linked with college where teaching professionals employed, age, nativity, professional development courses attended and number of M.Phil / Ph.D's produced. The capacity of applying their learned skills towards their professional and personal accomplishment with knowledge improvement were possible through professional development courses attended and with the number of M.Phil /Ph.D's produced.
Table 2 Relationship between Dependent Variables with EI on Self and Societal analysis

\begin{tabular}{|c|c|c|}
\hline Variables & EISA & EISOA \\
\hline AKA & .012 & $.284^{* *}$ \\
\hline EMF & .091 & $.248^{* *}$ \\
\hline EIAC & .106 & $.376^{* *}$ \\
\hline EISA & -- & $.133^{*}$ \\
\hline EISE & -- & $.215^{* *}$ \\
\hline EISM & -- & $.318^{* *}$ \\
\hline EICO & -- & $.435^{* *}$ \\
\hline
\end{tabular}

**. Correlation is significant at the 0.01 level (2tailed); *. Correlation is significant at the 0.05 level (2-tailed);

Dependent Variables: EISOA- EI on SocietalAnalysis; EISA- EI on Self-Analysis; AKAAndragogical Knowledge and Abilities; EMFEthical/and moral Framework; EIAC- Emotional intelligence Abilities and Competency; EISEEmotional Intelligence on Self-expression; EISMEmotional Intelligence on Self-motivation; EICOEmotional Intelligence on Conscientiousness.

It has been found from the above Table that EI on societal-analysis $(\mathrm{r}=0.284 ; \mathrm{p}<0.01) ;(\mathrm{r}=0.248 ; \mathrm{p}<0.01)$; $(\mathrm{r}=0.376 ; \mathrm{p}<0.01) ;(\mathrm{r}=0.133 ; \mathrm{p}<0.05) ;(\mathrm{r}=0.215 ; \mathrm{p}<0.01)$ and $(r=0.318 ; p<0.01)$ were significantly correlated with andragogical knowledge and abilities, EI abilities and competency, EI on self-expression, EI on selfawareness, EI on self-motivation and EI on conscientiousness respectively. Surprisingly EI on self-analysis were not correlated with any of the dependent variables.

Table 3 Regressions on EI on Self-Analysis

\begin{tabular}{|c|c|c|c|c|c|}
\hline Variables & $\mathbf{R}$ & $\mathbf{R}^{2}$ & $\boldsymbol{\beta}$ & $\mathbf{F}$ & $\mathbf{p}$ \\
\hline $\mathrm{C}, \mathrm{N}, \mathrm{MS}$, & & & 0.164 & & \\
$\mathrm{AE}$ & 0.392 & 0.153 & 0.158 & 1.976 & $<0.01$ \\
& & & -0.274 & & \\
& & & & \\
\hline
\end{tabular}

Dependent Variable: EI on Self-Analysis; p- Level of Significance

C-College; N-Nativity; MS-Marital Status; AEAcademic Excellence

The above Table 3 showed the result that college where the teaching professionals employed, nativity, marital status and academic excellence emerged as the most important predictors of EI on self-analysis. It predicted $15 \%\left(R^{2}=0.153\right)$ of the variance. Other background variables like gender, age, educational qualification, family size, family type, occupational 
status, type of occupation, employment status, service in present institution, monthly income, hobbies, skill development courses attended, professional development courses attended, number of M.Phil / Ph.D's produced, number of research publications made, number of consultancy works undertaken and type of Consultancy works undertaken did not change the percent of variance thus indicating the redundancy of these variables in predicting the emotional intelligence on self-analysis of teaching professionals. Beta coefficient for college where the respondents employed $(\beta=0.164)$, nativity $(\beta=0.158)$, academic excellence $(\beta=0.132)$ made positive contributions and marital status $(\beta=-0.274)$ made negative contribution. This suggested that college where teaching professionals employed, nativity and academic excellence has been predicted positively on emotional intelligence on self-analysis of teaching professionals. Marital status has been predicted negatively towards emotional intelligence on self-analysis of teaching professionals working in private self-financing colleges.

Table 4 Regressions on EI on Societal-analysis

\begin{tabular}{|c|c|c|c|c|c|}
\hline Variables & $\mathbf{R}$ & $\mathbf{R}^{2}$ & $\boldsymbol{\beta}$ & $\mathbf{F}$ & $\mathbf{p}$ \\
\hline FS, NRP & 0.343 & 0.118 & -0.137 & 1.458 & $<0.05$ \\
\hline
\end{tabular}

Dependent Variable: EI on Societal analysis; pLevel of Significance

FS-Family Size; NRP-Number of Research Publications made

The result from Table 4 revealed that family size and number of research publications emerged as the important predictors of emotional intelligence on societal- analysis. It predicted $11 \%\left(\mathrm{R}^{2}=0.118\right)$ of variance. The beta coefficients for family size $(\beta=-$ 0.137 ) and number of research publications made by teaching professionals $(\beta=-.0130)$ made negative contributions. This suggested that family size and number of research publications made by teaching professionals has been negatively contributed towards the emotional intelligence on societal-analysis. The other background variables like college, gender, age, nativity, educational qualification, marital status, family type, academic excellence, occupational status, type of occupation, employment status, service in present institution, monthly income, hobbies, skill development courses attended, professional development courses attended, number of M.Phil /Ph.D's produced, number of consultancy works undertaken and type of consultancy works undertaken did not change the percent of variance.

Table 5 Analysis of Variance (ANOVA) on Background variables with EI on Self and Societal Analysis

\begin{tabular}{|c|c|c|c|c|c|}
\hline DV/EIV & \multicolumn{2}{|r|}{ IV/BV } & MID & $\mathrm{F}$ & p \\
\hline \multirow{3}{*}{ EISA } & 0 & Tol Rural & 3.9125 & \multirow{3}{*}{3.758} & \multirow{3}{*}{$<0.05$} \\
\hline & $\mathrm{N}$ & Semi-Urban & 4.0678 & & \\
\hline & & Urban & 4.2520 & & \\
\hline \multirow{3}{*}{ EISOA } & \multirow{3}{*}{ MS } & Married & 4.5587 & \multirow{3}{*}{3.501} & \multirow{3}{*}{$<0.05$} \\
\hline & & Unmarried & 4.3614 & & \\
\hline & & Divorced & 5.0000 & & \\
\hline \multirow{4}{*}{ EISOA } & \multirow{4}{*}{ FS } & Below 3 Members & 4.5846 & \multirow{4}{*}{3.681} & \multirow{4}{*}{$<0.05$} \\
\hline & & 4-6 Members & 4.4946 & & \\
\hline & & 7-9 Members & 4.1818 & & \\
\hline & & 13-15 Members & 3.0000 & & \\
\hline \multirow{8}{*}{ EISOA } & \multirow{8}{*}{$\mathrm{H}$} & Reading & 4.0400 & \multirow{8}{*}{3.681} & \multirow{8}{*}{$<0.05$} \\
\hline & & Writing & 3.3333 & & \\
\hline & & Music & 4.2241 & & \\
\hline & & Sports & 3.5833 & & \\
\hline & & Cooking & 4.2143 & & \\
\hline & & Net surfing & 3.5714 & & \\
\hline & & All the Above & 4.3077 & & \\
\hline & & None of the above & 4.1556 & & \\
\hline \multirow{2}{*}{ EISOA } & \multirow{2}{*}{ PDCA } & MDP & 4.3750 & \multirow{2}{*}{3.681} & \multirow{2}{*}{$<0.05$} \\
\hline & & SDP & 3.6000 & & \\
\hline
\end{tabular}




\begin{tabular}{|c|c|c|c|c|c|}
\hline & & FDP & 4.5275 & & \\
\hline & & PDP & 4.3000 & & \\
\hline & & All the Above & 4.5556 & & \\
\hline & & None of the above & 4.5000 & & \\
\hline \multirow{6}{*}{ EISOA } & \multirow{6}{*}{ NPP } & Nil & 4.4973 & \multirow{6}{*}{2.425} & \multirow{6}{*}{$<0.05$} \\
\hline & & Less than 5 & 4.5439 & & \\
\hline & & $6-10$ & 4.7143 & & \\
\hline & & $11-15$ & 4.1667 & & \\
\hline & & $16-20$ & 4.0000 & & \\
\hline & & $21 \&$ Above & 5.0000 & & \\
\hline
\end{tabular}

p- Level of Significance

Background Variables (BV): N- Nativity; MS- Marital Status; FS- Family Size; H- Hobbies; PDCAProfessional Development Courses Attended; NPP- No. of M.Phil / Ph.D's Produced.

Dependent Variable: EISA- EI on Self-Analysis; EI on Societal analysis

Emotional intelligence on self-analysis (EISA) with nativity of teaching professional was analyzed to find mean difference between three groups like rural teaching professionals $(\mathrm{MD}=3.91) ;(\mathrm{p}<0.05)$, semiurban teaching professionals $(\mathrm{MD}=4.06) ;(\mathrm{p}<0.05)$ and urban teaching professionals (4.25); $(\mathrm{P}<0.05)$. The result revealed the value of mean difference for urban teaching professionals was greater than other groups like rural and semi-urban teaching professionals. Thus, teaching professionals living in urban area provided strong contribution towards emotional intelligence on self-analysis. Emotional intelligence on self-analysis (EISA) with marital status of teaching professionals was analyzed to find mean difference between three groups like married teaching professionals $(\mathrm{MD}=4.24) ; \quad(\mathrm{p}<0.01)$, unmarried teaching professionals $(\mathrm{MD}=3.81)$; $(\mathrm{p}<0.01)$ and divorced teaching professionals $(\mathrm{MD}=4.00) ;(\mathrm{P}<0.01)$. This result revealed that value of mean difference for married teaching professionals was greater than married and unmarried teaching professionals. Thus married teaching professionals contributed strongly towards emotional intelligence on self-analysis. Emotional intelligence on societalanalysis (EISOA) with marital status of teaching professionals was analyzed to find out the mean difference between three groups like married teaching professionals $\quad(\mathrm{MD}=4.55) ; \quad(\mathrm{p}<0.05), \quad$ unmarried $(\mathrm{MD}=4.36) ; \quad(\mathrm{p}<0.05)$ and divorced $(\mathrm{MD}=5.00)$; $(\mathrm{P}<0.05)$. The result provided the value of mean difference for divorced teaching professionals was greater than married and unmarried teaching professionals. Thus, divorced teaching professionals strongly contributed towards emotional intelligence on societal analysis. Emotional intelligence on societal analysis with family size of teaching professionals was analyzed to find mean difference between four groups of family size like family size below 3 members $(\mathrm{MD}=4.58) ;(\mathrm{p}<0.05)$, family size of 3-6 members $(\mathrm{MD}=4.49)$; $(\mathrm{p}<0.05)$, family size of 7-9 members $(\mathrm{MD}=4.18) ;(\mathrm{p}<0.05)$ and finally family size of $13-15$ members $(\mathrm{MD}=3.00) ;(\mathrm{p}<0.05)$. The result provided the value of mean difference for family size of teaching professionals below 3 members was greater than the family size of 4-6 members, family size of 7-9 members and family size of 13-15 members. Thus the family size below 3 members provided strong contributed towards emotional intelligence on societal analysis. Emotional intelligence on self-analysis (EISA) of teaching professionals with hobbies engaged were analyzed to find mean difference between eight groups of hobbies like reading $\quad(\mathrm{MD}=4.04) ; \quad(\mathrm{p}<0.01), \quad$ writing $(\mathrm{MD}=3.33) ;(\mathrm{p}<0.01)$, music $(\mathrm{MD}=4.22) ;(\mathrm{p}<0.01)$, sports $(\mathrm{MD}=3.58) ; \quad(\mathrm{p}<0.01)$, cooking $(\mathrm{MD}=4.21)$; $(\mathrm{p}<0.01)$, netsurfing (3.57) all the above $(\mathrm{MD}=4.30)$; $(\mathrm{p}<0.01)$ and none of the above $(\mathrm{MD}=4.15) ;(\mathrm{p}<0.01)$. The result indicated that teaching professionals who were engaged in all the hobbies like reading, writing, music, sports, cooking and netsurfing as their hobbies had greater score and contributed strongly on emotional intelligence on self-analysis. Emotional intelligence on societal analysis of teaching professionals were analyzed to find mean difference between six groups of professional development courses attended like MDP $(\mathrm{MD}=4.37)$; $(\mathrm{p}<0.05)$, SDP $(\mathrm{MD}=3.60) ; \quad(\mathrm{p}<0.05), \quad \mathrm{FDP} \quad(\mathrm{MD}=4.52) ; \quad(\mathrm{p}<0.05)$, PDP $\quad(M D=4.30) ; \quad(p<0.05), \quad$ All the above $(\mathrm{MD}=4.55) ; \quad(\mathrm{p}<0.05)$ and none of the above $(\mathrm{MD}=4.50) ; \quad(\mathrm{p}<0.05)$. The result proved that the teaching professionals who attended FDP had greater score and contributed strongly on emotional intelligence on societal-analysis. Emotional intelligence on societal-analysis (EISOA) of teaching 
professionals were analyzed to find mean difference between six groups of number of Ph.D's produced, No Ph.D's produced $(\mathrm{MD}=4.49) ;(\mathrm{p}<0.05)$, less than 5 $(\mathrm{MD}=4.54) ;(\mathrm{p}<0.05), 6-10(\mathrm{MD}=4.71) ;(\mathrm{p}<0.05), 11-$ $15(\mathrm{MD}=4.16) ;(\mathrm{p}<0.05), 16-20(\mathrm{MD}=4.00) ;(\mathrm{p}<0.05)$ and 21 and above $(\mathrm{MD}=5.00) ;(\mathrm{p}<0.05)$. The result indicated that the teaching professionals who has produced 21 and above research scholars had greater score and contributed strongly on emotional intelligence on societal-analysis.

\section{Implications \& Discussions}

The social analysis refers to evaluation of issues related to social characteristics, quality of life, social services and social justice within the society. Hence, teaching professionals are linked with learners within society; it comprises of individuals, learners and environments. The study conducted by (Joseph \& Newman, 2015) suggested that background variables like: population, age and composition of gender, ethnic characteristics, leadership arrangements and social divisions are investigated to analyze social analysis. Interestingly, results of the study showed inverse relationship between societal-analysis with marital status, family size and number of research publications made by the teaching professionals. The result revealed that mean difference for teaching professionals living in urban area differed significantly towards EI on self-analysis (EISA). Surprisingly, mean difference for divorced teaching professionals showed high significance towards ethical and moral framework (EMF) and EI on societal-analysis (EISOA). The mean difference of married teaching professionals contributed highly towards EI on self-analysis (EISA). The college where teaching professionals employed, nativity and academic excellence were positive predictors and marital status was the only negative predictor for emotional intelligence on self-analysis. The result expressed that EI on self-analysis has been predicted positively by college where teaching professionals employed, nativity and academic excellence and negatively for marital status of teaching professionals. The EI dimensions improve abilities and competency to control emotional instability are self-awareness, self-confidence, self-control and conflict management (Lakshmipriya et al. 2016). The present research study clearly highlighted the correlation between family size and number of research publications made by teaching professionals to that of emotional intelligence abilities and competency (perceiving, thinking, segmenting emotions, empathy, accumulation of teamwork, increase of communication and acceleration of attentiveness). The results revealed that significant correlations have been found between various background variables like: college where teaching professionals employed and their academic excellence with EI on self-analysis. Also, there exists significant and inverse correlation between marital status with EI on self-analysis. The findings focused on college where teaching professionals' are employed at present and their academic excellence related to self-analysis. Moreover, self-analysis among teaching professionals necessitated them to understand their individual strengths to improve their self and is more concerned in their quality. Self-analysis is the application of psycho-analytic techniques and theories to an analysis of one's own personality and behavior, especially without the aid of a psychiatrist or other trained person (Lakshmipriya, 2015). Thus, it is clear from the present study that emotional intelligence is the desirable context among teaching professionals for self-analysis.

\section{Suggestions \& Conclusion}

Teaching professionals' positive effect of emotional intelligence increases with age, experience and subjective well-being. Affective experiences become more stable as age and gender reflects emotional intelligence on self-analysis and self-expression over societal-analysis. Thus, the findings highlighted that background variable age predicted emotional intelligence and teaching effectiveness. The expressive behaviours towards emotional intelligence on self-analysis, self-expression, self-motivation, societal-analysis and application learning skills were concentrated at better-quality in the college where teaching professionals were employed. Thus, the research study spotlighted appropriate emotional intelligent training and development which towards their individual and professional effectiveness has been conceded from colleges where the teaching professionals were employed. Teaching professionals as per their nativity of their livelihood in which the respondents viewed that urban area provides better conveniences. Hence, utilize conveniences for 'self' and 'societal realization'. This attributed high ethical and moral framework, which maintained their effectiveness in teaching, learning, research and consultancy activities which were carried out. Teaching professional's who have good teaching, learning, research and consultancy records better survive in their professional career. The findings 
showed that emotional intelligence variables like selfanalysis and societal analysis. The innovative programmes of emotional intelligence can be practiced at different intervals within the institution or workplaces, which can be practiced for 'self' and 'societal enhancement' of teaching professionals. The findings implied that emotional intelligence can be diligently learned, inculcated and enhanced through self-analysis, self-expression, self-motivation, selfobservance, self-introspection and skills management in accordance with their continuous experiential learning. In furtherance, innovative programmes in teaching andragogy and curriculum can be implemented to provide teaching professionals with additional skills to meet personal, professional and societal challenges. The personality, behaviour, interest, attitude and emotions of teaching professionals affect students/learners' behavioural pattern will benefit the society.

\section{References}

1. Boyatzis, R E, Goleman, D \& Rhee, K. (2002) "Clustering competence in emotional intelligence: Insights from the Emotional Competence Inventory (ECI)", In R. Bar-On \& J. D. A. Parker (Eds.), The handbook of emotional intelligence: Theory, development, assessment and application at home, school and in the workplace, JosseyBass, San Francisco.

2. Cherniss, C. (2010) "Process-designed training: A new approach for helping leaders develop emotional and social competencies", Journal of Management Development, 29(5), 413-431.

3. Cowie, R. (2011) 'Emotion: Concepts and Definitions", Emotion-Oriented Systems, Cognitive Technologies, 9-30.

4. Day, C. (2007), "Teachers Matter: Connecting Lives, Work and Effectiveness". Open University Press, Berkshire.

5. Derksen, J. (2010) "Does a self-report measure for emotional intelligence assess something different than general intelligence?" Personality and Individual Differences, 32, 37-48.

6. Elias, M J. (1992) “A measure for adaptation to problematic academic and under personal tasks of middle school", Journal of Middle School Psychology, 30, 41-57.

7. Elias, M. (1997) “The Missing Piece: Making the case for greater attention to Social and emotional learning in the schools", Education Week, 17(5), 36-38.
8. Goleman, D (1995), Emotional intelligence: Why it can matter more than IQ, Bloomsbury Publishing, London.

9. Goleman, D. (1997), Emotional intelligence: Why it can matter more than IQ, Bloomsbury Publishing, London.

10. Goleman, D. (1998), “What makes a leader?”, Harvard Business Review, 76(6), 93-102.

11. Igbo, J N., Nwaka, R N., Mbagwu, F, \& Mezieobi, D. (2016), "Emotional intelligence as a correlate of social and academic adjustment in South East GEO-political zone of Nigeria”, ABC Journal of Advanced Research, 5(1), 9-20.

12. Joseph, D L., \& Newman, D A. (2015), “Emotional intelligence: An integrative meta-analysis and cascading model", Journal of Applied Psychology, 95(1), 54-78.

13. Lakshmipriya, S., \& Saradhamani, R. (2015) "Building Emotional Intelligence: Hands-On Strategies for Inner Strength and Cognitive Enhancement amongst Youngsters", Perspectives of Entrepreneurship and Management Research, 59-69.

14. Lakshmipriya, S., Saradhamani, R., \& Ganesan, R. (2016), "Inter-Relationship of Factors in Configuring Emotional Intelligence Amongst Teaching Community - A Sociological Perspective”, Asian Journal of Research in Social Sciences and Humanities, Asian Research Consortium, 6(4), pp. 368-385.

15. Mayer, J D., \& Salovey, P. (1997) "What is emotional intelligence? In P. Salovey and D. Sluyter (eds.): Emotional development and emotional intelligence: educational implications", Basic Books, New York, 3-31.

16. Myers, D G. (2001), Psychology, Worth Publishers, USA.

17. Palmer, P J. (2010), The courage to teach, Jossey Bass, San Francisco.

18. Singh, D. (2002), Emotional intelligence at work: A Professional Guide, Sage Publications, New Delhi.

19. Sutton, M. (2006), "Emotional intelligence and competence in a knowledge citizen's world", South African Journal of Information Management, 8(4), 11-15.

20. Ozer, E., Hamarta, E. \& Deniz, M E. (2016), "Emotional intelligence, core-self evaluation and life satisfaction”, Psychology, 7, 145-153. 